\title{
Culto a las aguas y divinidades orientales en el Lugo romano: los posibles santuarios de San Roque y Bóveda
}

\author{
A. Rodríguez Colmenero *
}

Es bastante lo que se ha escrito ya sobre la presencia de divinidades orientales en la España Romana y concretamente en el sector NW de la península '. Bracara, Asturica o Aquae Flaviae presentan ejemplos epigráficos suficientes como para evidenciar un culto floreciente a $/ \mathrm{sis}^{2}$, a Serapis ${ }^{3}$, a Cybeles ${ }^{4}$, a Caelestis ${ }^{5}$, a Frugifero o Saturno Africano ${ }^{6}$, etc.

\footnotetext{
* Universidad de Santiago de Compostela.

'LeITE de VAsconcelos, J., Religióes da Lusitânia, vol. 3 (reimp. facsimilada de la primera edic., 1913). Lisboa 1981; LAMBRINO, S., «Les divinités orientales en Lusitanie et le Santuaire de Panoias", BEP, XVII, 1953; García Y Bellido, A., «El Culto a Sérapis en la Península Ibérica». BRAH, CXXXIX, 1957; Les Religions Orientales dans l'Espagne Romaine, Leiden 1967 (EPRO); "Lápidas votivas a deidades exóticas halladas recientemente en Astorga y León», BRAH, 163, 1968, 197 ss; ETIENNE, R., "Les syncrétismes religieux dans la Péninsule lbérique à l'époque impériale». Les syncrétismes dans les religions grecque et romaine. Paris 1973; NONY, C. D., «A propos des nouveaux procurateurs d'Astorga», Arch. Esp. Arq, 43, 1970, 197 ss; Blanco Freideiro, A., «El Panteón Romàno de Lucus Augusti». Actas del Coloquio Internacional sobre el Bimilenario de Lugo. Lugo 1977, pags. 107 ss; LE Roux, P., «Lucus Augusti, capitale administrative au Haut Empire", Actas del mismo Coloquio, pág. 83 ss.; CANTO, A. M., "Saturninus Augusti Libertus", Gallaecia, 3-4, 1979, 301 ss.

${ }^{2}$ Especificamente HüBnen en CIL, II, 2416, inscripción de Bracara Augusta; BaLIL, A., "EI Culto a Isis en España», Cuadernos de Trabajos de la Escuela Española de Historia y Arqueología en Roma, VII, 1956, pág. 3-13; ALVAR, J., "El Culto a Isis en Hispania», en el simposio La Religión Romana en Hispania. Madrid (Ministerio de Cultura), 1981.

${ }^{3}$ Garcia, A., y Bellido, Lápidas.... , Op. cit. pág. 196 ss; El Culto... , Op. cit., vol. 139 ; Nony, D., A propos... 196-200; Wagner, C. G.-Alvar, J., «El Culto a Serapis en Hispania», en el simposio La religión..., Op. cit., pág. 323 ss.

${ }^{4}$ Cardozo, M., Algumas inscriçoes das regiões de Chaves e vizinhanzas. Chaves 1943, 11 ss; Russel Cortez, "Lápides Romanas do Museu de Chaves", Viriatis, I, 1957, 101 ss; Rodriguez Colmenero, A., Galicia Meridional Romana. Deusto-Bilbao 1977, 101 ss; Tranor, A., La Galice Romaine. Paris 1981, 334; BendalA, M., "Las Religiones Mistéricas en la España
} 
Se ha pretendido, incluso, relacionar los vaciados en la roca del Conjunto Sacro de Panoias (Vila Real) con prácticas de incubatio y el culto a Serapis, por otra parte presente en una de las inscripciones que alli se exhiben ${ }^{7}$, asi como a sus renombrados misterios, de los que se habla en la misma inscripción, porque, sin duda, se representaban en aquel lugar. Pero no se había pasado de ahí, por cuanto faltaba la identificación de otros santuarios pertenecientes a divinidades orientales.

Aunque lo que vamos a exponer dista de poseer una completa fundamentación científica y pertenece al mundo de la mera suposición, nos parece que es la hipótesis orientalista la que mejor encaja en la explicación de dos monumentos singulares aparecidos en los alrededores de Lugo, uno de ellos sobradamente conocido de todos, Santa Eulalia de Bóveda, y el otro inédito y en trance de excavación todavía por parte de los Servicios Muncipales de Arqueología, que dirige María Covadonga Carreño. Se trata de un estanque ritual aparecido recientemente en los jardines de San Roque, a menos de cien metros de la muralla y a la vera de las vías XIX y XX del Itinerario de Antonino, a su salida de la porta toletana, hoy de San Pedro.

\section{PISCINA RITUAL DE SAN ROQUE}

Su descubrimiento se produjo como consecuencia de la exhumación de parte de una gran necrópolis romana de incineración-inhumación en el solar del antiguo Mesón de Aguiar, precisamente en uno de sus lindes y cuando se procedía a clausurar los trabajos arqueológicos del verano de 1988 (lám. l,1). Se trata de un insólito lacuus, al que entraba y del que

Romana", en el simposio La Religión Romana en Hispania, Madrid 198| (Ministerio de Cultura).

${ }^{5}$ Garcia, A., y Bellido, "El Culto a la Dea Caelestis en la Península Ibérica», BRAH, CXL (1957), 451 ss; "Deidades Semiticas en España Antigua», Sefarad, XXIV (1964), 242 Ss; LE Roux, P., Lucus Augusti..., Op. cit., pág. 83 ss; BLanco, A., El Panteón..., Op. cit., pág. 107 ss.

${ }^{6}$ LE GLAY, P., Saturne Africain, Histoire. París 1966, 120 ss; BLECH, M., "Saturn in Hispania», Madrider Mitteilungen, 19, 1978; CAnto, A. M., Saturninus..., Op. cit., pág. 301 ss.

7 Sobre el conjunto sacro pueden verse: COnTADOR DE ARgote, A., Memorias para a historia eclesiástica do Arzebispado de Braga. Lisboa 1732, I, 325 ss; LeITE DE VAsconCELos, J., Op. cit., II, 187 ss, III, 468; Lambrino, S., Les divinites..., Op. cit., 106 ss; Garcia, A. y Bellido, El Culto..., Op. cit., 327 ss; Blazquez, J. M., Religiones..., Op. cit., 180 ss; Tranoy, A., La Galice. ., 337; Rodriguez Colmenero, A., Aquae Flaviae I. Fontes Epigráficas. Braga 1987, 138 ss. 
Culto a las aguas y divinidades orientales en el Lugo romano ...

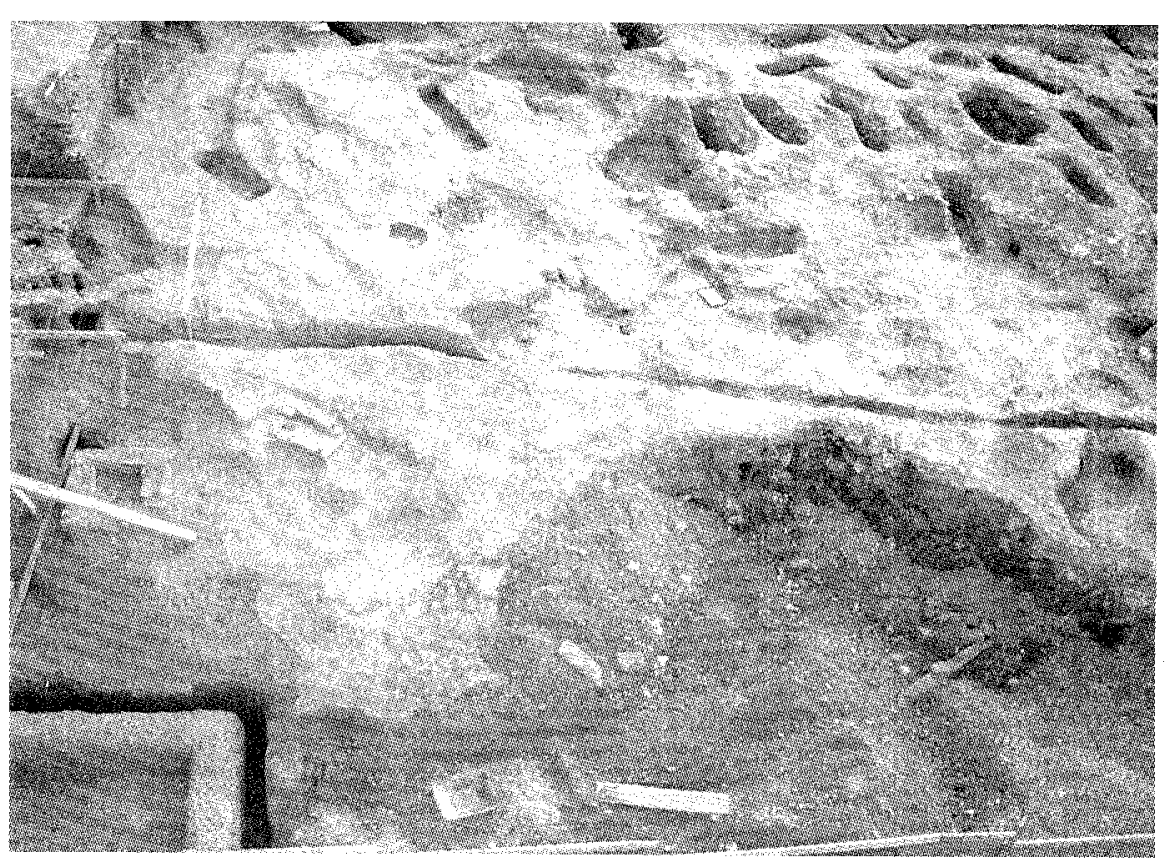

Lám. 1.1. Necrópolis de San Roque (panorámica).

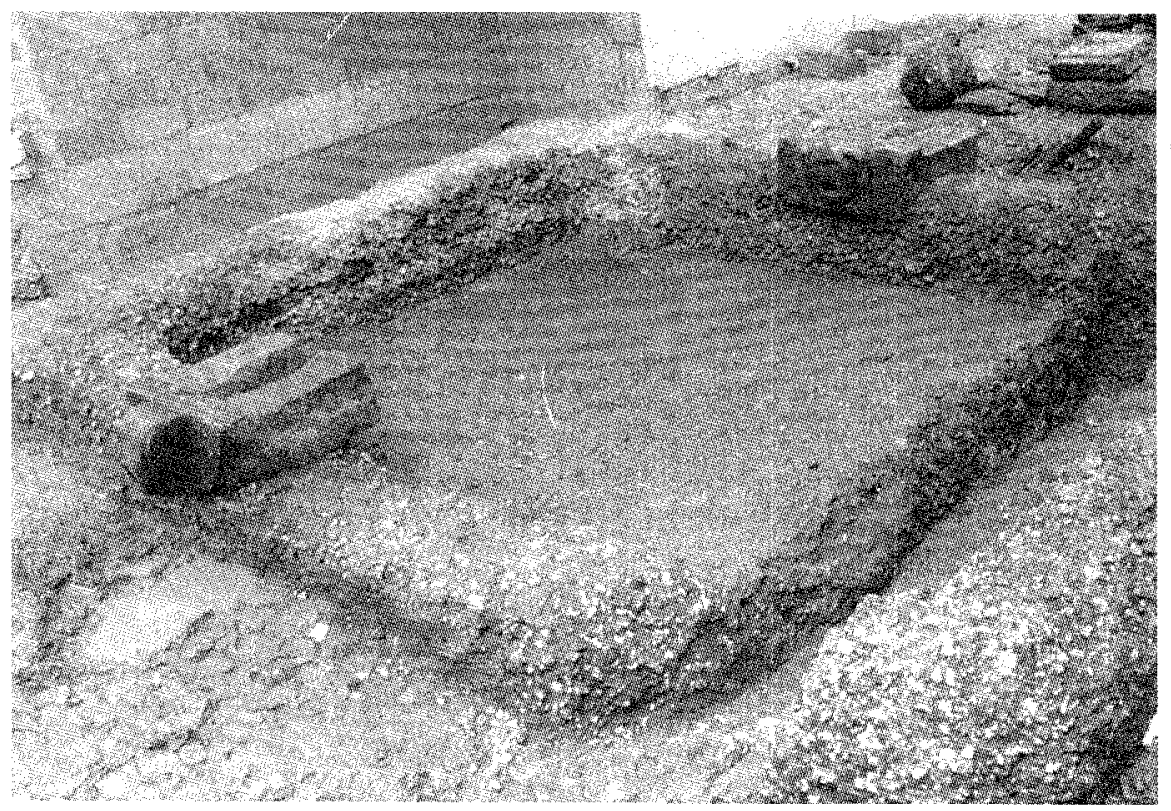

Lám. 1.2. San Roque. Piscina (vista general). 
saía el agua por el orificio de dos grandes bloques graníticos perforados, que lucen sendos mascarones en su cara externa, el de entrada una faz de esfinge o medusa y el de salida la testuz de un carnero con la cornamenta vuelta hacia abajo.

El estanque mide 6 por 4,40 por 0,80 metros exteriores y está fabricado a base de opus caementicium, ofreciendo su superficie interior enfoscada con argamasa más fina de cal y arena, a la que recubre otra tenue camada, todavía más decantada, de cal cernida y polvillo de teja. Se asienta en firme basamento de mortero, a través de cuyas roturas se ve asomar un fuerte lecho de cantos rodados (lám. I,2). Por ahora, no se han descubierto otras estructuras que puedan relacionarse con el monumento, salvo los cimientos muy arrasados de los endebles muros de una estancia que parece haber coincidido, por el sur, precisamente por el lado del desagüe, con el ámbito de la robusta piscina antes descrita. Sin embargo aparentan ser de cronología menos temprana porque parecen asentarse sobre un suelo artificial de imperfecto opus signinum fabricado en la banda contigua a la pared meridional del estanque con los elementos sobrantes de esta misma construcción (lám. $/ /, 1)$. De todas maneras, existen vestigios de otros muros más sólidos, posiblemente relacionados con la piscina y su época de construcción, de los que no podemos decir mucho, dado el corto ámbito en que se mueve la excavación. Por el momento, no podemos adelantar más en un sector en el que secularmente se ha operado un alto grado de destrucción, al encajarse por las inmediaciones del estanque, e incluso sobre su mismo ámbito, las zanjas de los distintos servicios de la ciudad.

Quedan, sin embargo, suficientes vestigios cerámicos y elementos sueltos de construcción como para suponer que existió un edificio, sin duda de finalidad cultual, en el entorno, al igual que un potente horizonte de carbonización que, dada la profundidad relativa en la que aparece, en modo alguno puede relacionarse con la actividad de un horno cerámico al que inmediatamente vamos a referirnos y si, tal vez, con un posible ustrinum, a la vista, sobre todo, de la existencia en las proximidades de una gran necrópolis mixta de incineración-inhumación (lám. l,1).

Por otra parte, y aunque pertenecientes a un momento posterior, existen en las cercanías, más o menos inmediatas, un horno cerámico de baja época romana, 0 , tal vez, altomedieval, y diversos enterramientos que pertenecen a la gran necrópolis excavada en 1988. Además, existen noticias poco concretas de que en las proximidades pudo haberse levantado el teatro romano de la ciudad, parte de cuyas gradas serían discernibles 
Culto a las aguas y divinidades orientales en el Lugo romano ...

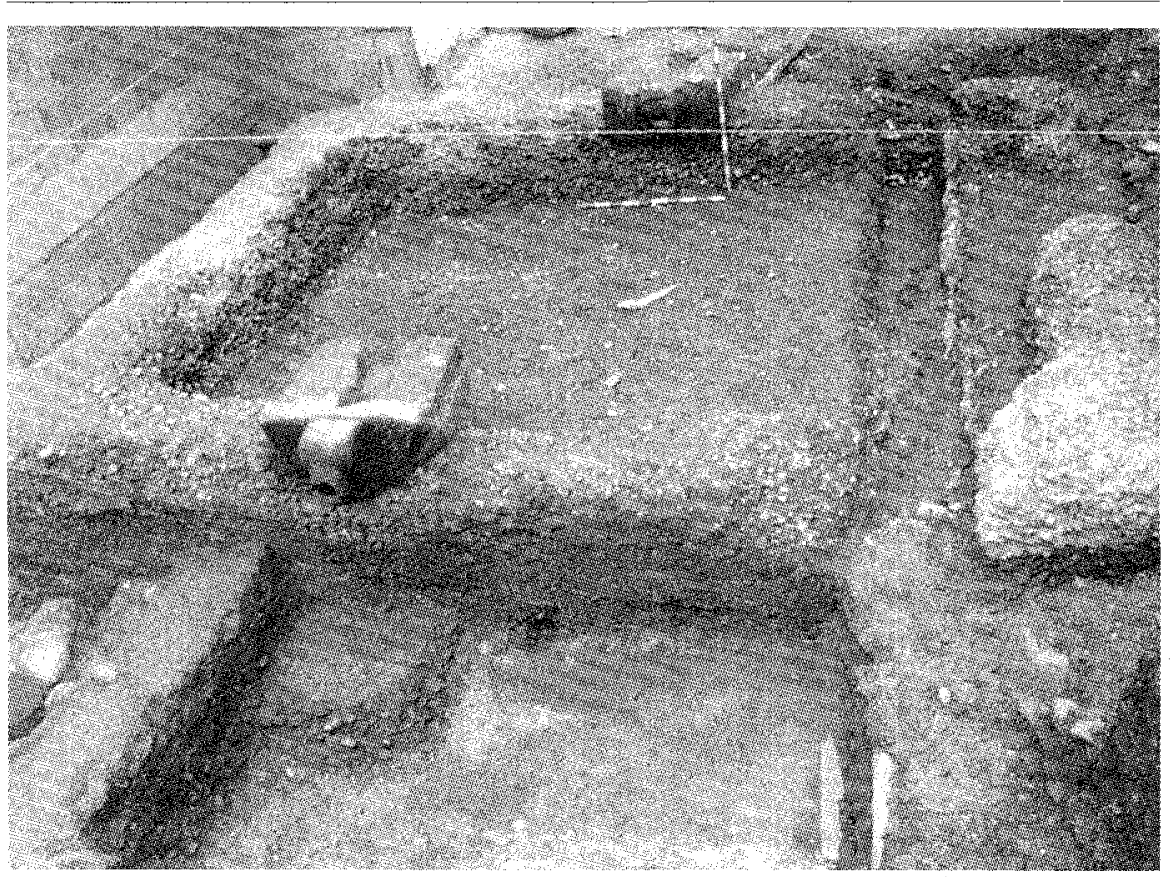

Làm. Il.1. San Roque. Piscina (detalle del desagüe).

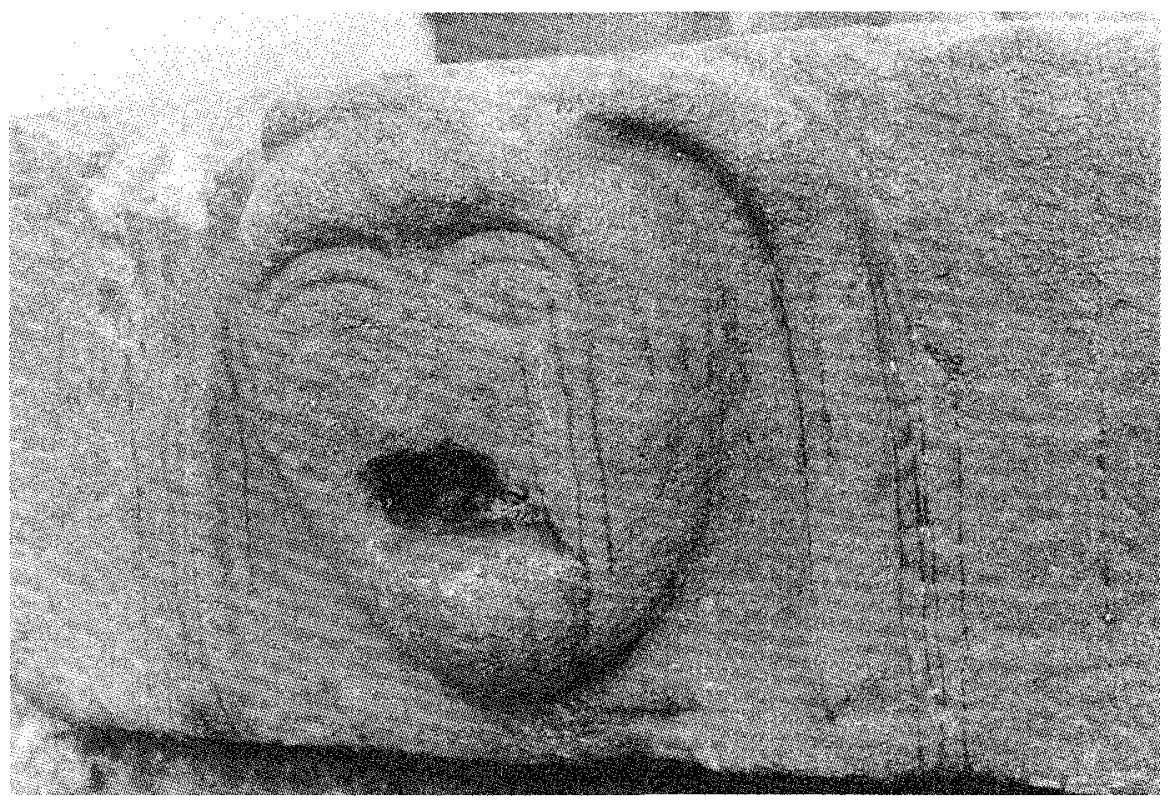

Lám. II.2. San Roque (medusa o esfinge). 
todavía en el siglo $\times V^{8}{ }^{8}$. En todo caso, nada puede vislumbrarse hoy en día en un área desde antiguo avaramente ocupada por las edificaciones.

Nos vemos precisados, por lo tanto, a analizar e interpetar nuestro monumento sin más contexto válido que la necrópolis a la que inicialmente hemos hecho alusión, lo que, sin duda, va a dificultar la obtención de resultados más diáfanos. Conscientes de estas limitaciones, intentaremos, por lo tanto, aventurar una interpretación que, por otra parte, creemos fundamentada.

Nuestra base de partida obedece a tres presupuestos lógicos: que posiblemente el estanque tuvo algo que ver con la vecina necrópolis, ya que se integra dentro de su ámbito; que, dada la presencia y simbología de los relieves, no se trata de un estanque construido con fines meramente utilitarios; que se trata de una muestra arquitectónica no aislada, puesto que debió de formar parte de un conjunto constructivo más amplio, que sólo podemos advinar, pero no determinar, dada la estrechez del ámbito de excavación con que contamos.

Era preciso, por lo tanto, buscar una explicación a la presencia de este monumento $y$, tras varios intentos en diversas direcciones, nos ha parecido que es la hipótesis orientalista la que mejor explica los hechos. A este respecto, el libro ya no reciente de Robert $A$. Wild sobre la importancia del agua en el culto de Isis y Serapis ${ }^{9}$ ha resultado para nosotros un excelente guía, como antes lo habian sido los estudios de F. Cumont, los recogidos en la edición de F. Derchain, H. Frankfort, T. Hopfener ${ }^{10} \mathrm{o}$, para la península, los de Leite de Vasconcelos, Scarlat Lambrino o Garcia y Bellido ${ }^{11}$.

En el Mediterráneo helenístico y grecorromano existen numerosos santuarios dedicados a las divinidades egipcias Isis y Serapis, en muchos de los cuales se han hallado evidentes vestigios de la importancia que el agua debió de haber tenido en las ceremonias relacionadas con aquellas divinidades. Al parecer, el origen de la relación agua-santuarios se remonta a las criptas subterráneas de las épocas faraónica y tolemaica. cuya finalidad inicial era la medida del caudal del río proporcinal a la extensión a irrigar en el valle, práctica que continuó en vigor durante el

\footnotetext{
8 Pallares y Galoso, J., Argos Divina. Santiago de Compostela, 1700, 19 ss.

${ }^{9}$ WILD, R. A., Water in the cultic worship of Isis and Serapis. Leiden 1981 (EPRO).

${ }^{10}$ Cumont, F., Oriental Religions in Roman Paganism. Chicago 1911; Derchain, Ph., (edit.), Religions in Egypte hellenistique et romain. París 1969; Frankfort, H., Ancient Agyptian Religion. New York 1948; Hopfner, J., Plutarch über lsis und Osiris. Praga 1940.

11 Leite de Vasconcelos, J., Religiões... , III, 465 ss; Lambrino, A., Les divinites..., 106 ss; Garcia, A. y BeLlido, Las Religiones..., Op. cit. anteriormente.
} 
período de dominación romana ${ }^{12}$. Sin embargo, la finalidad meramente utilitaria de estos medidores del nivel del Nilo evolucionan poco a poco hacia la vertiente cultual, de tal manera que $\mathrm{H}$. W. Fairman sugiere que pudieran haber servido a la vez para suministrar agua del Nilo para las ceremonias litúrgicas y no para las necesidades ordinarias ${ }^{13}$. En consecuencia, el agua que se destinaba a las ceremonias sagradas debería ser almacenada en el momento de la crecida del río.

Pero en época helenística y romana el culto a Isis y Serapis se extiende por todo el mediterráneo y, por razones de distancia, resulta imposible reproducir las ceremonias litúrgicas utilizando el agua del Nilo. Se recurre entonces a las aguas de otros manantiales próximos, que inunden una cripta calcada en los modelos nilóticos e imiten la crecida estacional y benefactora de dicho río, hecho que, según Merkelbach ${ }^{14} \mathrm{se}$ celebraba en una gran fiesta anual, que podía coincidir, sobre todo en los países de bajo índice pluviométrico, con la llegada del periodo de lluvias, época en que se inundaban las criptas sagradas, aumentando, como el Nilo en el verano, su nivel.

Ahora bien, los contenedores no nilóticos del agua del Nilo, obtenida de una manera "sacramental», en cierta manera, en los distintos puntos del imperio romano, y sobre todo a partir del siglo I de la era, no seguian en todos los casos el modelo estricto de la cripta, adoptando algunas veces el de simple piscina situada, no en el templo sino al lado del mismo, como sucede en Pérgamo y Frauenberg (Austria) ${ }^{15}$. $Y$ es precisamente el modelo de Frauenberg el que mejor coincide, por sus características, con nuestro monumento. W. Modrijan, su excavador, lo califica de pilón para contener agua ${ }^{16}$. Está situado a un lado del templo y en un plano inferior, precisamente en donde las curvas de nivel acentúan la inclinación del terreno, como sucede en el caso de Lugo. Aquella es cuadrada, con unas medidas de 2,90 por 2,60 m exteriores (recordamos que la de San Roque mide 6 por $4,40 \mathrm{~m}$ ) y sus paredes han sido levantadas a base de cascajo y mortero, tal como sucede con la nuestra. Sin embargo, su profundidad alcanza los 1,50 m frente a los 0,80 de la de San Roque, pese a lo cual, posee ésta mayor capacidad.

\footnotetext{
12 PLIN, N. H. 5.10.58, coment. en WILD, R., Water..., 25-26.

${ }^{13}$ FalRman, H. W., “Worship and Festivals in Egyptian Temple». BJRL, 37 (1954), pág. 172.

${ }^{14}$ Merkelbach, H., Isisteste in griegisch-römischen Zeit. Daten und Riten. Meinsehein am Glan 1963, 14-19.

${ }^{15}$ WILD, R., Water..., 54.

${ }^{16}$ ModrIJAN, W., «Frauenberg bei Leibntz-seit alters ein 'Heiliger Berg'», BlHeim 27 (1953), $56-68$.
} 
En la pared sur de la de Frauenberg se advierte una abertura de 1,60 metros de anchura practicada en el borde, por la que rebasaba el agua de la piscina cuando esta se llenaba. Similares rebajes parecen haber existido en las tres paredes restantes, mientras en la de San Roque, orificios de entrada y salida corresponden a las aberturas practicadas en dos bloques esculturados, situándose el de entrada catorce centímetros más alto que el de salida.

Por otra parte, en Frauenberg existe un canal de avenamiento de 0,80 metros de anchura, que procede del subsuelo del pórtico del templo. $Y$, aunque no se sabe con exactitud, lo más probable es que se nutriese de las aguas del impluvium del recinto sagrado, que fluirian intermitentemente (dependiendo del régimen pluviométrico) hacia la piscina en cuestión, que, como la de San Roque y todas las conocidas dentro del ámbito del imperio romano, no posee desagüe a nivel de suelo. En nuestro caso, sin embargo, lo problemático es determinar la procedencia del canal, que, sin duda, llegaba del norte, a juzgar por los retazos encontrados durante la excavación de la necrópolis y por la existencia de un rico manantial, hoy cegado, existente antaño hacia aquella parte ${ }^{17}$. Pero, tanto la nuestra como la de Frauenberg son las únicas que no están situadas en los sótanos del templo, pese a no tratarse de simples piscinas dedicadas a rutinarias abluciones rituales. En todo caso, lo que en ambos depósitos se intentaba era reproducir la crecida fecundante y anual del Nilo mientras el agua iba subiendo de nivel en la piscina, según quiere R. Will ${ }^{18}$ porque ésta y no otra era el agua de la fertilidad y de la vida, de la que Isis y Serapis eran señores, según uno de los papiros de Oxyrinco estudiados por Peek ${ }^{19}$.

Pero la piscina cultual de San Roque se diferencia de las de su género por los originales mascarones que luce a modo de relieves, cuyo simbolismo resulta inexcusable interpretar.

Ambos están orientados en el mismo sentido, hacia el sur, si bien no se encuentran alineados. Ello nos ha hecho sospechar de si no habrá existido un tercer relieve con perforación para desagüe, puesto que es el de esta función el que se encuentra descentrado, que vendria a marcar el vértice perdido de una disposición triangular.

${ }^{17}$ El grado de destrucción del canal al que nos estamos refiriendo era acentuado $y$, de conectar con el mascarón de entrada al estanque, tendría que haberlo hecho vertiendo en él su líquido desde un plano ligeramente superior, ya que en el zócalo contiguo y situado al mismo nivel no se advertía vestigio alguno de encaje o embutimento.

${ }^{18}$ WILD, R., Water..., 60.

${ }^{19}$ W. PEEK, Der Isishymus von Andros und verwandte Texte. Berlin 1930. 
Como ya queda indicado, el más septentrional o de entrada, de 1 por 0,80 por $0,40 \mathrm{~m}$, muestra en su cara anterior la máscara de una esfinge o medusa, cuyas caracteristicas son (lám. /I,2): faz femenina de perfil ovalado, ojos saltones y de mirada opaca, cejas y frente bien marcados al igual que los dos penachos de la melena, que cuelgan a ambos lados de la faz en simétrica distribución y equilibrio. La boca, alterada por una perforación irregular, que permitia el paso del agua, ofrece un perfil notablemente degradado.

El otro bloque moldurado ofrece medidas similares pero distinta morfología, ya que adopta una marcada silueta barquiforme (lám. III,1). En la parte anterior, testuz insculpida de carnero con la cornamenta vuelta en círculo casi completo hacia abajo. Ningún otro rasgo diferenciador, como si de obra inacabada se tratase; tan sólo un agujero circular en el morro cónico del óvido.

Un estanque que posee tales aditamentos no puede ser meramente utilitario, tiene que poseer mucho de cultual, y más estando inserto en una necrópolis. Cierto que máscaras de Júpiter Amón asociadas a fuentes o a depósitos de agua aparecen en diversos lugares, como Deir-el-Kuelah (Libano), Museo de los Oficios de Florencia o la monumental de la Villa

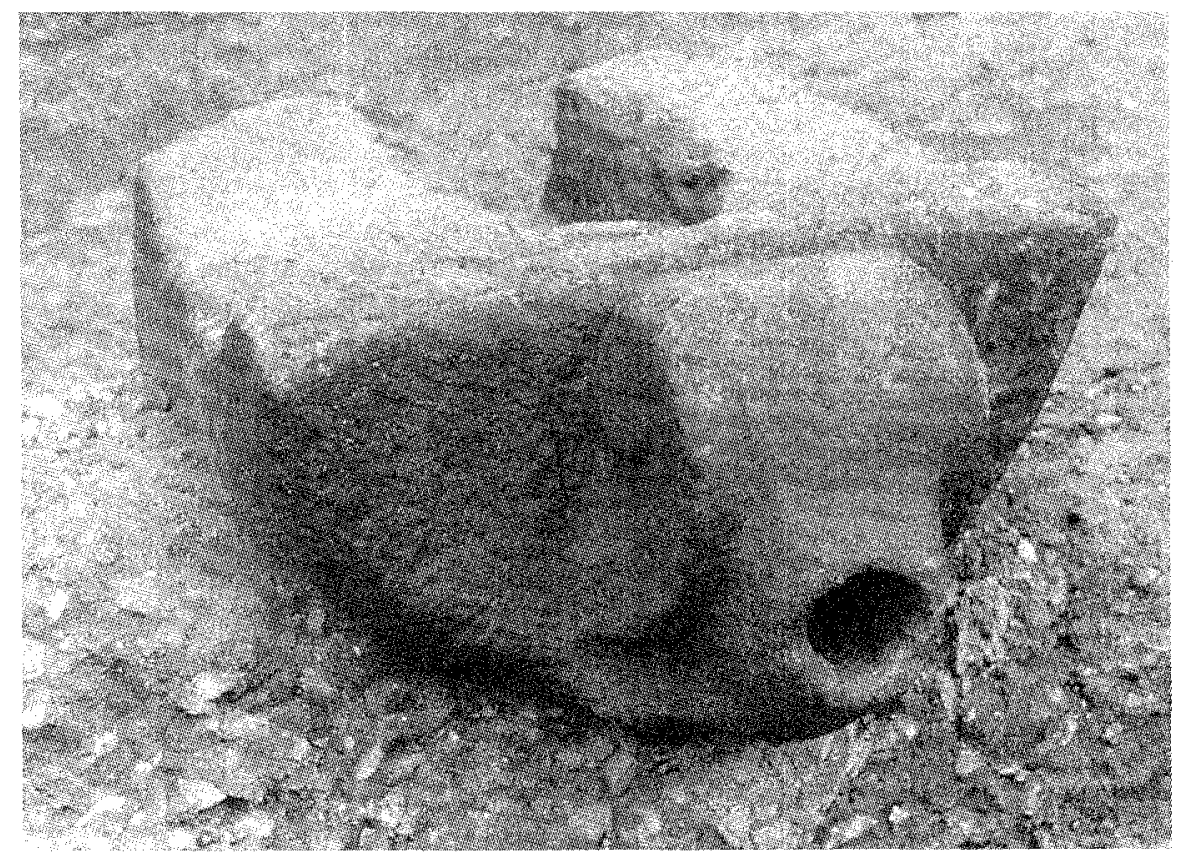

Lám. III.1. San Roque (carnero). 
Albana ${ }^{20}$. Pero ninguno de ellos in situ, por lo que no se puede juzgar acerca de su finalidad meramente estética o ritual, como creemos nosotros, y más cuando aparece, como en nuestro caso, asociado a la esfinge. En el arte funerario áulico el carnero y la medusa, o la esfinge, aparecen frecuentemente representados, tanto en las estelas como en los mausoleos, según ha puesto de manifiesto para Roma D. Boschung ${ }^{21}$ y para todo el imperio Diana Kleiner ${ }^{22}$, entre otros. Las cabezas de carnero, normalmente simbolizando a Jủpiter-Amón, aparecen ya en época tiberiana y son comunes en el reinado de Claudio, tanto que se las llega a representar, incluso, en punzones de cerámica aretina, según ha puesto de relieve recientemente Mariano del Amo para la necrópolis cristiana de Tarragona, al ocuparse de la cerámica itálica allí aparecida ${ }^{23}$. R. Turcan ha sugerido que las cabezas de carnero se refieren a ceremonias purificadoras que seguían a los entierros, y las cabezas de Júpiter-Amón usadas en un contexto militar constituian un poder protector, junto con los grifos y águilas en las esquinas de los mausoleos y las cabezas de medusa en el centro ${ }^{24}$ (sarcófago de la Galería de los Uffizi en Florencia, si bien procede de Roma, etc). Por otra parte, y conservando este mismo sentido protector, la medusa y Júpiter-Amón con cuernos aparecen en la coraza de una estatua imperial de Dalkingen, Obstalkreis (Baden-Würtemberg) hallada en las excavaciones realizadas por Dieter Plank a finales de la década de los años setenta. El significado protector resulta aquí evidente.

Según las teorías de Turcan, por lo tanto, en nuestro caso se trataría del primer supuesto, un contexto funerario, que es el que, en realidad aparece como más claro si se tiene en cuenta, además, que el espeso horizonte de carbonización que se advierte en las proximidades de la necrópolis y del estanque mismo pudiera ser indicio de la existencia de un ustrinum. Nótese, sin embargo, en la lámina correspondiente (lám. I,1) que las zonas cultual y funeraria parecen estar nítidamente separadas por un largo canal que se percibe todavía en la foto. Por ello, creemos que a los aspectos escatológicos pudieran unirse aquí los simplemente cultua-

${ }^{20}$ Blondel, K., "Ammon", en Ch. Daremberg-Ed. Saglio, Dictionnaire des Antiquités Grecques et Romaines, 1er A-B. Graz 1969, 230 ss.

${ }^{21}$ Boschung, D., Antike Grabaltäre aus den Nekropolen Roms. Berlín 1987.

${ }^{22}$ KLEINER, D., Roman Imperial Funerary Altars with Portraits. Roma 1987.

${ }^{23}$ DEL AMO, M., «La cerámica aretina de la necrópolis cristiana de Tarragona», Pyrenae, $9,1973,16 \mid$ ss.

${ }_{24}$ Turcan, R., Les Cultes Orientaux dans le Monde Romain. París, 1989. También para áreas geográficas concretas: Budischovsky, M. C., "Jupiter Ammon et Medusa dans les forums du Nord de l'Adriatique». Aquileia Nostra, XLIV, 1973, 201-220; BIANCHI, L., Le Stele Funerarie della Dacia. Roma 1985. 
les en la dirección que antes hemos mentado y que estarían conexionados con la funcionalidad misma de la piscina y del santuario, que sin duda alguna poseyó a su lado y que habría que explicar, según antes se ha indicado, relacionándolos con ritos religiosos de procedencia oriental, egipcia concretamente. Sin embargo no podemos adelantar acontecimientos porque las excavaciones en curso pueden depararnos algunas sorpresas. Por otra parte, la necesidad de conexionar a la esfinge con Isis y a Júpiter Amón con Sérapis, como catalizadores, el uno de todas la diviniades masculinas y la otra de las femeninas, sólo podría realizarse, en teoría, en el Siglo III, en la época de florecimiento de un intenso sincretismo, en donde a Júpiter-Amón se le llamaria Optimo Máximo y a Serapis Panhtheo o Ipsisto porque, en la prática, y atendiendo a los últimos decubrimientos, los influjos religiosos orientales parecen haber comenzado antes.

En resumen, atendiendo al estanque mismo y a su posible función y contexto, podemos sospechar de la existencia de un Iseum, Serapeum o ambas cosas juntas; si atendemos solamente a los mascarones, la finalidad meramente funeraria queda subrayada. Falta atar los cabos de una deseada conexión entre ambos aspectos. En todo caso, un culto floreciente a divinidades orientales queda testimoniado en la ciudad a través de la epigrafía, por medio de dos dedicatorias a Caelestis y una a Frugiferus o Saturno Africano ${ }^{25}$.

\section{SANTA EULALIA DE BÓVEDA}

Monumento romano famoso, con abundante bibliografía, pese a lo cual se le sigue etiquetando, por parte de la generalidad de los estudiosos, de enigma. No vamos a ocuparnos en esta ocasión de la historia de los descubrimientos ni de realizar una pormenorizada descripción arqueológica, cosa que efectuamos en un estudio más extenso que está a punto de salir a luz, sino solamente de intentar una explicación a su original arquitectura.

El conjunto monumental de Santa Eulalia poseía dos plantas perfectamente integradas y coetáneas, sin duda comunicadas entre sí por una escalera posterior diferente de la muy endeble que descubrió López Martí

\footnotetext{
${ }^{25}$ Blanco, A., El Panteón..., Op. cit., pág. 107 ss; le Roux, P., Lucus Augusti.., 83 ss.
} 
al efectuar el primer vaciado en $1926^{26}$. La planta superior ha sido casi totalmente destruida, salvo un retazo de pared septentrional superpuesta y coincidente exactamente con el tramo correspondiente de la nave inferior. Posee ventana rectangular cerca del suelo y conserva el inicio de la curvatura de la bóveda de cañón que recubría todo el ámbito.

En la parte inferior pueden diferenciarse todavía hoy tres partes (lám. III,2): el nártex o atrio, el cuerpo abovedado central y el pequeño ábside rectangular del fondo del templo.

El nártex es un rectángulo de 6,40 por $1,45 \mathrm{~m}$, al que cierra un frente enmarcado por dos gruesos pilastrones en los extremos y compartimentado por dos columnas incompletas y postizas en el sector central. Lo recubría una bovedilla de medio cañón, pintada con un esquema de rombos y de la que se conservan tan sólo los arranques (lam. IV,1).

Se accede al cuerpo central por una puerta de 1,17 $\mathrm{m}$ de anchura, provista de los rasgados correspondientes para encajar la hoja y cubierta por un arco ultrasemicircular de ladrillo con trasdós granítico. A ambos lados de la puerta, ventanas cuadradas coronadas por sendos triangulillos ciegos. En el interior destaca una gran estancia perfectamente cuadrada, 6,40 por 640 metros, cubierta toda ella por una gran bóveda de medio cañón decorada con pinturas en su totalidad.

Son discernibles en ella, todavía, los arcos de ladrillo constitutivos de la cimbra o armazón, existiendo en cada uno de los muros laterales sendas hornacinas adinteladas de 0,88 por 0,51 cada una de ellas (lám. $I V, 2)$.

Esta única nave primitiva fue subdividida en tres, en una etapa posterior, por medio de arquerías longitudinales sobre columnas de mármol, de las que las cuatro centrales enmarcaban un rectángulo de 3,50 por 2,60 metros, originariamente estanque o piscina, según después se verá.

Al fondo de la gran nave, un nuevo recuadro, más estrecho, que hace de presbiterio, de 2,85 por 1,56, al que se accede a través de un gran arco peraltado de $1,30 \mathrm{~m}$ de anchura. Su límite posterior está constituido por un muro, en el que se abrió desde el inicio una gran ventana de doble hoja, de altura similar a la de una puerta y con el alféizar situado a solo $0,70 \mathrm{~m}$. del suelo (lám. anterior).

${ }^{26}$ Sobre la excavación misma, López MARTI, L., Santa Eulalia de Bóveda. Descripción y gráficos sobre el monumento alli existente. Lugo 1934. Aceptable fotografía de la escalera en cuestión en otro trabajo del mismo autor: «Las excavaciones de la Iglesia de Santa Eulalia de Bóveda». BRAGall. XXII, 204, 1928, pág. 323. 
Culto a las aguas y divinidades orientales en el Lugo romano ...

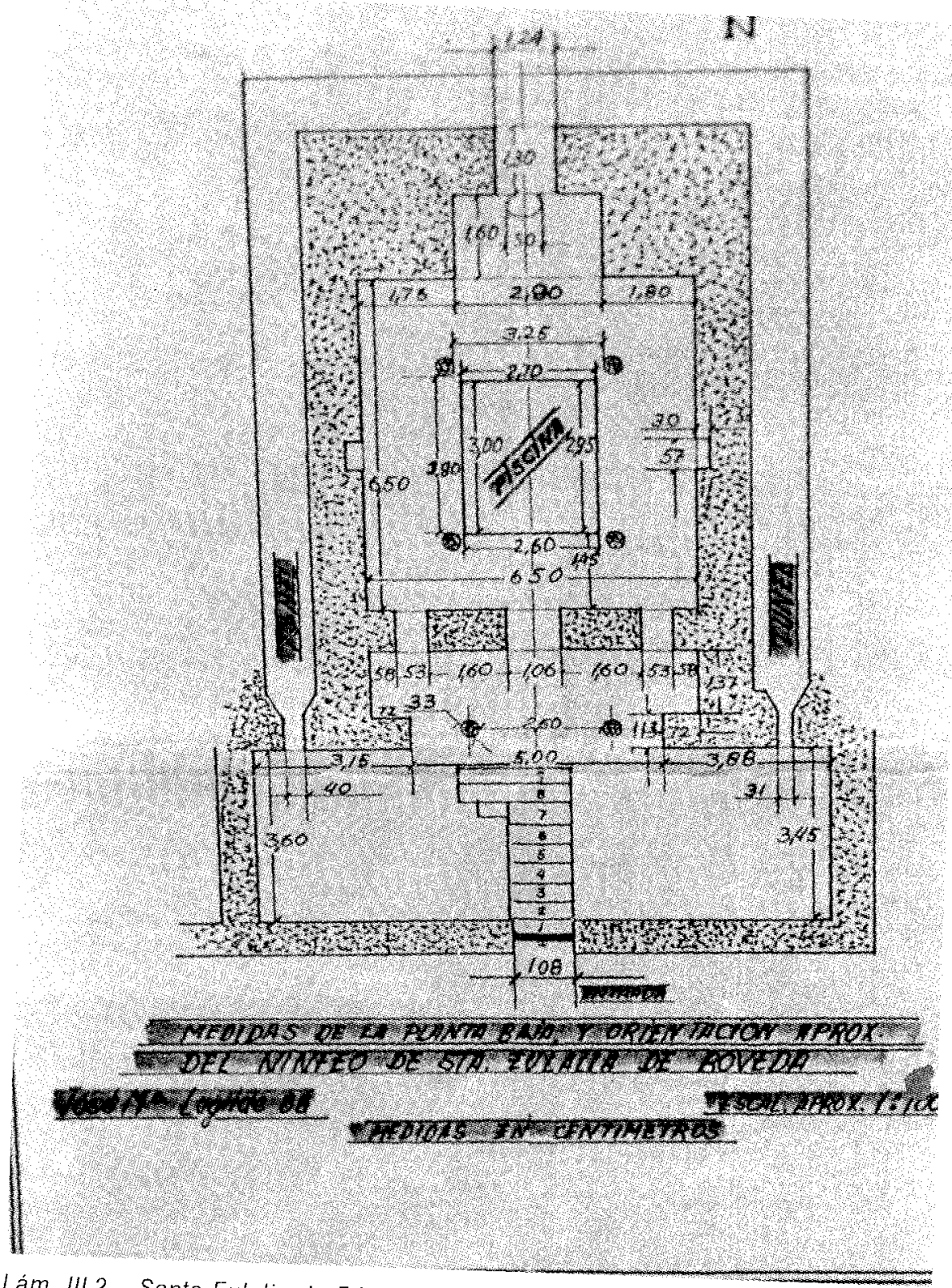

Lám. III.2. Santa Eulalia de Bóveda (planta). 


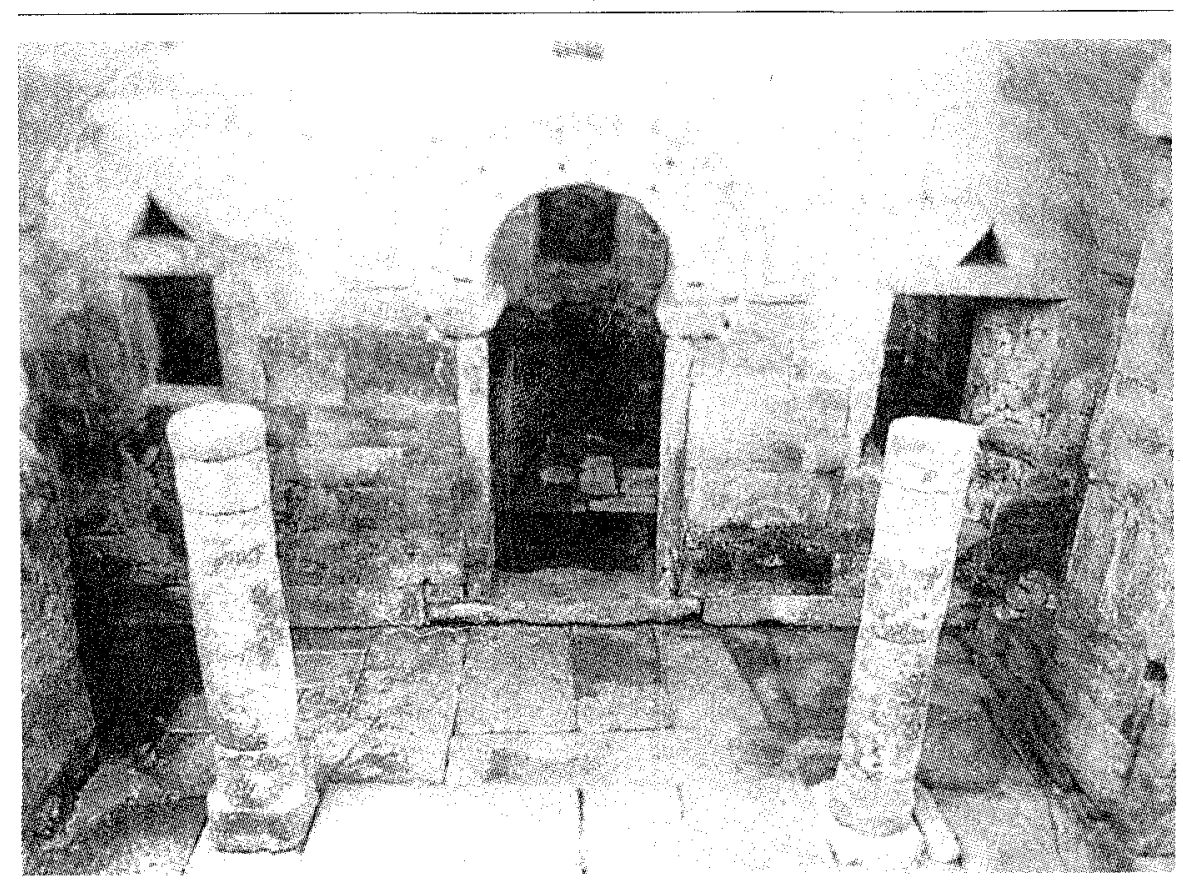

Lám. IV.1. Santa Eulalia de Bóveda (nártex).

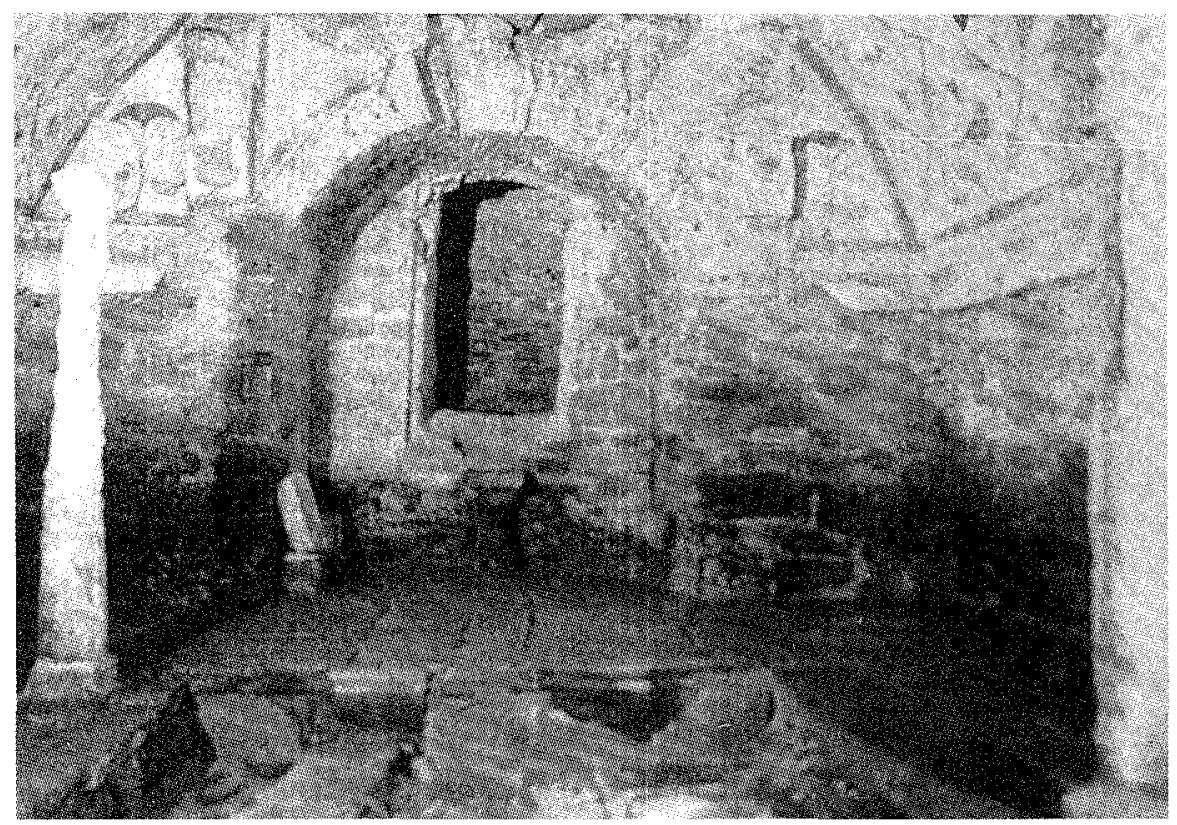

Lám. IV.2. Santa Eulalia de Bóveda (interior). 
INTERPRETACIONES MÁS RELEVANTES SOBRE LA NATURALEZA DEL MONUMENTO

Una de las primeras que se barajó fue la hipótesis cristiana, en el sentido de que se trataria de un lugar de culto de esta naturaleza ${ }^{27}$. Años más tarde, sin embargo, García y Teijeiro opina que se trata de un templo pagano y sólo pagano ${ }^{28}$. Schlunk, en 1935 , le atribuye un significado funerario, fundándose, sobre todo, en los relieves existentes en algunos de los sillares del nártex ${ }^{29}$. Algún tiempo después, Gómez Moreno se inclina por pensar que el cuerpo bajo del edificio no tiene nada de cristiano y sugiere que si no se tratará de un lugar de culto relacionado con divinidades orientales ${ }^{30}$. Antes, tanto Sánchez Cantón como Alberto del CastiIlo, se habian inclinado por pensar que se trataba de un ninfeo, hipótesis que hace suya Chamoso Lamas en la década de los cincuenta ${ }^{31}$, si bien apostilla que en una etapa posterior habria sido convertida en una basílica cristiana.

Ya en la década de los setenta, Celestino F. de la Vega se inclina por ver en Santa Eulalia el martirium de Prisciliano, sin descartar que hubiese podido ser ninfeo en datas anteriores ${ }^{32}$. Es el momento en que M. Núñez considera que la primera parte del monumento es uno más de los edificios de la llamada «arquitectura ritual castrexa», tipo Briteiros o Augas Santas, y la segunda un ejemplo más del llamado arte asturiano, dado el evidente paralelismo entre las pinturas de Bóveda y las de Santullano de Pravia ${ }^{33}$, para lo que se apoya en un trabajo anterior de Schlunk ${ }^{34}$. En

\footnotetext{
${ }^{27}$ Breves notas firmadas por F. del Boletín de la Real Academia Gallega del mes de diciembre de 1926 y febrero y marzo de 1927.

${ }^{28}$ Garcia, M., y Telueiro, Un vistazo al subtemplo de Santa Eulalia de Bóveda sito en tierras de Mera de Lugo. Lugo 1933, pág. 31 ss.

${ }^{29}$ Schlunk, H., "Santa Eulalia de Bóveda", en Das Siebente Jahrzehnt. Festschrift zum 70 Geburstag von Adolph Goldsmidt. Berlin 1935, 1 ss.

${ }^{30}$ Gomez Moreno, A., "Santa Eulalia de Bóveda», en Misceláneas de Historia, Arte y Arqueologia. Madrid 1949, pág. 415 ss.

${ }^{31}$ Chamoso Lamas, M., "Sobre el origen del monumento soterrado de Santa Eulalia de Bóveda». Cuad. Est. Gall., VII, 1952, pág. 131 ss.

${ }^{32}$ Fernandez de la Vega, C., Santa Eulalia de Bóveda, un enigma histórico. Lugo 1971, VII.

${ }^{33}$ Núñez Rodriguez, M., Historia da Arquitectura Galega. Santiago de Compostela 1972.

${ }^{34}$ Schlunk, H. - Berenguer, M., La Pintura Mural Asturiana de los siglos ix y x. Oviedo 1957, pág. 46 ss.
} 
época más reciente, sin embargo, otros autores acaban por atribuir a época romana las pinturas de Santa Eulalia de Bóveda ${ }^{35}$.

\section{UNA MIRADA CRITICA}

Un pormenorizado estudio del edificio de Santa Eulalia de Bóveda nos ha llevado a descubrir una serie de peculiaridades constructivas que anteriormente no habian sido descritas y que pueden influir bastante en la comprensión de su finalidad específica. No es éste el momento indicado para detenernos en su estudio, pero baste con adelantar que, entre otras observaciones originales, podemos aportar las de que: los fundamentos de las paredes del nártex se apoyan en lo que parecen cornisas invertidas, lo que presupone un edificio anterior al actual; las dos columnas de tambores que compartimentan el frente del nártex son mero pastiche, existiendo los fustes de las auténticas amontonados en las proximidades; los triangulillos ciegos situados encima de las ventanas del cuerpo principal fueron vanos reales inicialmente, quedando obturados cuando se dividió en tres la única nave y se enlució y pintó toda la superficie interior; que la puerta de ingreso al cuerpo principal era de hoja única y se trancaba por adentro, teniendo que existir necesariamente comunicación con la planta superior o estancias de la parte posterior todavia no descubiertas; la gran ventana del fondo del ábside poseyó originariamente doble hoja y debió de responder a cometidos de tipo ritual porque para simple vano de comunicación con la planta superior sobrarian su excesiva anchura y la elevación de su base sobre el suelo; en fin, que el levantamiento de la actual fábrica de Santa Eulalia de Bóveda, con sus dos plantas, fue proyectada y ejecutada en un mismo momento, resultando evidente que la planta inferior está intimamente relacionada con la superior, formando parte de una única y contemporánea estructura, comunicándose, sin duda, por la zona del ábside.

\section{UNA NUEVA HIPÓTESIS DE TRABAJO}

Somos de la opinión de que en Santa Eulalia de Bóveda existieron, al menos, tres momentos constructivos.

\footnotetext{
${ }_{35}$ Abad Casal, L., "Aportación al estudio del Santa Eulalia de Bóveda", XV Congreso Nacional de Arqueologia. Lugo 1977. Zaragoza 1978, pág. 917 ss.; La Pintura Romana en España. Sevilla-Alicante 1982, 14 ss.
} 
Existiría, en primer lugar, un edificio de menores dimensiones que el actual, cuyas cornisas serian aprovechadas para apoyo y fundamento de los pilastrones del atrio del que permanece todavía en pie actualmente. Intuimos, incluso, que sus elementos de derribo, por otra parte sillares de bellísima factura, fueron empleados en el pórtico, fachada e hiladas bajas de las paredes de la actual edificación, esto es, hasta donde alcanzó su número, supliéndose el resto de la fábrica con opus latericium o simple opus caementicium. Debió de tratarse de un edificio singular y sin duda de carácter religioso o ritual, si se tiene en cuenta su semienterramiento inicial, que pudo haber guardado relación estrecha con una fuente y su adecuada captación y aprovechamiento. En todo caso, el hecho de que la atarjea de desagüe de la piscina pase bajo el muro de la fábrica actual y de que su arqueta de registro para la regulación del nivel del agua se encuentre bajo las losas del nártex, según ya indicara Chamoso ${ }^{36}$ demuestran que la piscina o es anterior o, cuando menos, contemporánea del edificio. Con todo, la arquitectura observada en la piscina en modo alguno la semeja a un ninfeo, como, por ejemplo, el de Munigua, estudiado, entre otros, por Hauschild ${ }^{37}$.

La segunda fase y más importante estaría representada, debido a causas que no podemos determinar, por la destrucción de la obra anterior y la construcción de la que ahora existe en el lugar. El edificio, en sí, posee una cierta envergadura, ya que se le dota de dos plantas intercomunicadas. La inferior con bello nártex en donde se situan los relieves a los que después nos referiremos, que pudieron haber pertenecido ya a la fase anterior y ser meramente reaprovechados en la presente, dada la aparente simetria de algunos de ellos y el desorden de colocación que se advierte en otros; y la superior, hoy casi totalmente destruida. De todas formas, tambien es posible que dichos relieves fuesen ejecutados «ad hoc» para esta etapa, dada la perfecta simetría de los sillares que los sustentan. En todo caso, y contrariamente a lo que sucede con las pinturas, predomina en las representaciones la figura humana, siendo la más significativa, aunque no la más decorativa, la de los tullidos, que parecen estar relacionados con las propiedades curativas del manantial. Esta última circunstancia, la existencia de la expresión «mersit» en un fragmento de mármol perteneciente a una inscripción más extensa aparecido sobre el enlosado del local, la inscripción PRO SALUTE... de un ara fragmentada, que, por haberse encontrado formando parte de un muro, pudo ha-

${ }^{36}$ Chamoso, M., Op. cit., pág. 243.

${ }^{37}$ HAuschild, Th., «Excurs. Bemerkungen zu Therme und Nymphäum von Munigua». Madrider Mitteilungen, 18, 1977. 
ber pertenecido a esa fase inicial del santuario a la que ya nos hemos referido $\mathrm{y}$, finalmente, el dato complementario suministrado por Chamoso de la existencia de una piscina en la nave central, piscina que en la actualidad es plenamente observable, parecen abonar la hipótesis de que se trata de un lugar de culto en el que intervienen de manera destacada las aguas salutiferas; lo que no quiere decir un ninfeo necesariamente, por cuanto el agua interviene tambien de forma destacada en la celebración de cultos a las divinidades orientales. De lo primero existen abundantes testimonios en el ámbito del imperio y también repartidos por diversos lugares de la peninsula hispana.

No parece, por lo tanto, que fuese construido con finalidad cultual cristiana este edificio de dos plantas, que, sin embargo, seria adaptado a dicho cometido en época posterior. Lo más probable es que se trate de un santuario pagano, en cuya parte inferior, comunicada mediante espléndido vano, tanto con estancias situadas tras el actual testero como con la planta superior, se celebraban ceremonias lustrales y salutiferas, trátese o no de las ninfas, según se dirá.

La adaptación cristiana, detectable más por la advocación de una patrona de antiquísimo renombre, según ya expresara Pierre David para otros casos similares ${ }^{38}$, que por la simbología de sus pinturas o lo definido de su función, vendría dado por la tercera fase, reconocible, según se ha dicho, en la aplicación de una fuerte capa de argamasa estucada, que obturaría los tragaluces triangulares de las ventanas, en la que se plasma un magnífico manto de decoración geométrica, pero sobre todo naturalista ${ }^{39}$. Es ahora, además, cuando se divide la nave en tres ámbitos paralelos, separados por arquerias sobre columnas de mármol, con una particularidad, y es que las cuatro columnas marmóreas que sustentan las arquerías están dispuestas definiendo una piscina central, que bien pudo haber funcionado en esta época como baptisterio, puesto que la profundidad que Chamoso le atribuye, unos $70 \mathrm{~cm}$, asi como el hecho de poseer pavimentado su fondo, aunque sea con losas irregulares, según el mismo autor, vienen a otorgar cierto fundamento a esta posibilidad. Pero antes, se hace preciso explicar la funcionalidad de las fases iniciales del edificio, que es en donde radica lo esencial del problema. $Y$ se nos ha ocurrido que, a la vista de lo dicho para la piscina de San Roque,

\footnotetext{
39 Dadv, P., "Les Saints Patrons d'Eglises", en Etudes Historiques sur la Galice et le Portugal. París 1947, pág. 234 ss.

39 Hemos comprobado fehacientemente cuanto queda dicho valiéndonos de una escalera para acceder a la parte interior de dichos triángulos. La argamasa que después recibió la pintura fue aplicada contra un triangulillo-tapón granítico labrado ad hoc.
} 
interpretable en un esquema cultual de divinidades orientales, si podría aplicársele un cliché semejante, teniendo en cuenta especialmente determinadas peculiaridades arqueológica a las que iremos haciendo referencia.

Los elementos que más directamente sugieren en Santa Eulalia la existencia de un Iseum o Serapeum durante la primera y segunda fases del edificio vendrían determinados, tanto por la existencia de la seudocripta misma como por la morfología de la piscina y de su canal regulador del desagüe, así como por la simbología de los relieves, interpretables, aunque no exclusivamente, en esta misma dirección.

La cripta, en rigor, no es tal, porque, dada la ubicación en declive del terreno natural, poseia una fachada totalmente descubierta en su parte oriental. No obstante, cumple los requisitos de lugar oculto, subterráneo con relación a la nave superior en las otras tres caras. Por otra parte, piénsese que la inmensa mayoría de los templos consagrados a Isis y Serapis dentro del ámbito del imperio romano, si tenemos en cuenta los registros e R. Will, entre otros ${ }^{40}$, cuentan siempre con criptas contenedoras del agua sagrada del Nilo en el ámbito subterráneo del recinto sagrado, salvo en los casos dichos al referirnos al estanque de San Roque, en donde la cripta se suple con la construcción de piscinas en el terreno en declive de las inmediaciones. Sin embargo, existen en estos santuarios otras criptas dedicadas al culto, como para el de Thesalónica descubrió Makaronas ${ }^{41}$, como existen piscinas para abluciones, en general situadas a la entrada de los templos, que nada tienen que ver con las piscinas cultuales para el agua del Nilo. Nada de extraño, por lo tanto, que la solución arbitrada para Santa Eulalia fuese también transicional entre la cripta subterránea y el ámbito abierto, por una parte, y la cripta cultual asociada a la función de contener el agua del Nilo, por otra. En todo caso, el elemento más novedoso vendría dado por la concordancia en la amplitud de ámbitos entre la planta superior, teóricamente dedicada a templo propiamente dicho, y la inferior, relacionada con el agua y las ceremonias lustrales.

La morfología de la piscina existente en Santa Eulalia es similar a la de otros santuarios dedicados a divinidades egipcias, como sucede en Ras el Soda o Cyrene ${ }^{42}$, en el Iseo del recinto de Apolo, por no citar el

\footnotetext{
40 WiLd, R., Water..., 25 ss.

${ }^{41}$ Makaronas, C. I., "Hanaskafe parà tò Sarapeion» (en griego). Makedonika 1 (1940), 46465.

${ }^{42}$ WILD, R., Water..., 120 ss.
} 
Serapeum de Delos ${ }^{43}$. De todas maneras, en Santa Eulalia la originalidad consistiría en un canal de desagüe a nivel de fondo de piscina, al que irian a parar otros varios de captación de agua procedentes de los laterales del edificio, contrariamente a lo que se dijo para la piscina de San Roque y sucede con los iseos y serapeos conocidos. Dicho canal de desagüe sería, a la vez, colector y regulador del nivel del estanque, según se desprende de las noticias suministradas por Chamoso y hemos comprobado accidentalmente y de visu recientemente mientras se remodelaba el pavimento de la planta inferior. De tal manera que, obturando con una piedra oval el agujero de salida del canal a la altura del ángulo SE del nártex o en algún posible registro regulador situado más afuera, se lograba mantener a una altura constante el nivel del agua, simbolizándose así, cuando ello era preceptivo, la crecida del Nilo y sus aspectos benefactores. No estamos excluyendo con esta explicación otras posibles interpretaciones relacionadas con divinidades de las aguas y hasta es posible que sean igual de congruentes otras interpretaciones. Personalmente, sin embargo, nos convence más la que estamos dando.

En lo que respecta a los relieves que lucen los sillares del nártex, todo parece indicar que abonan una interpretación similar.

Uno de los más significativos es el de un sillar de la corta pared norte, en donde es perceptible una escena con dos personajes lisiados, como demuestra la rigidez y deformidad de algunos de sus miembros respectivos, que parecen buscar la curación en una supuesta inmersión en el agua, que, por el contexto, debe de suponerse (lám. $V, 1)$. El paralelo más allegado sería el del lisiado de la pátera de Otañes, que, apoyado en un cayado, ofrece un holocausto sobre ara a la Salus Umeritana ${ }^{44}$, mientras un personaje noble, sentado en una silla de respaldo cóncavo, recibe un vaso de agua de manos de su fámulo, otro personaje en edad viril derrama sobre el foculus de un nuevo altar el agua que vierte con una pátera y el mercader se afana, ayudado por un esclavo, en llenar el tonel que se encuentra anclado sobre la pesada raeda de dos ejes del que tira un par de briosas mulas. De esta manera, quedarían plásticamente representadas las virtudes del agua: salud para el lisiado, juventud para el viejo, solaz para el noble, utilidad para el comerciante.

\footnotetext{
${ }^{43}$ Roussel, P., «Les Santuaires égyptiens de Delos et d'Eretrie», Revue Egyptologique NS 1 (1919) 81-92; WILD, R., Water..., 36.

${ }^{44}$ La bibliografia existente en torno a esta pátera es bastante abundante, siendo A. GARCia y Bellido, Esculturas Romanas de España y Portugal. Madrid 1949, pág. 467, lám. 345 uno de sus más ilustres estudiosos. Tambien BlazQuez, J. M., Religiones Primitivas e Hispania. Madrid 1961, 188 ss.
} 


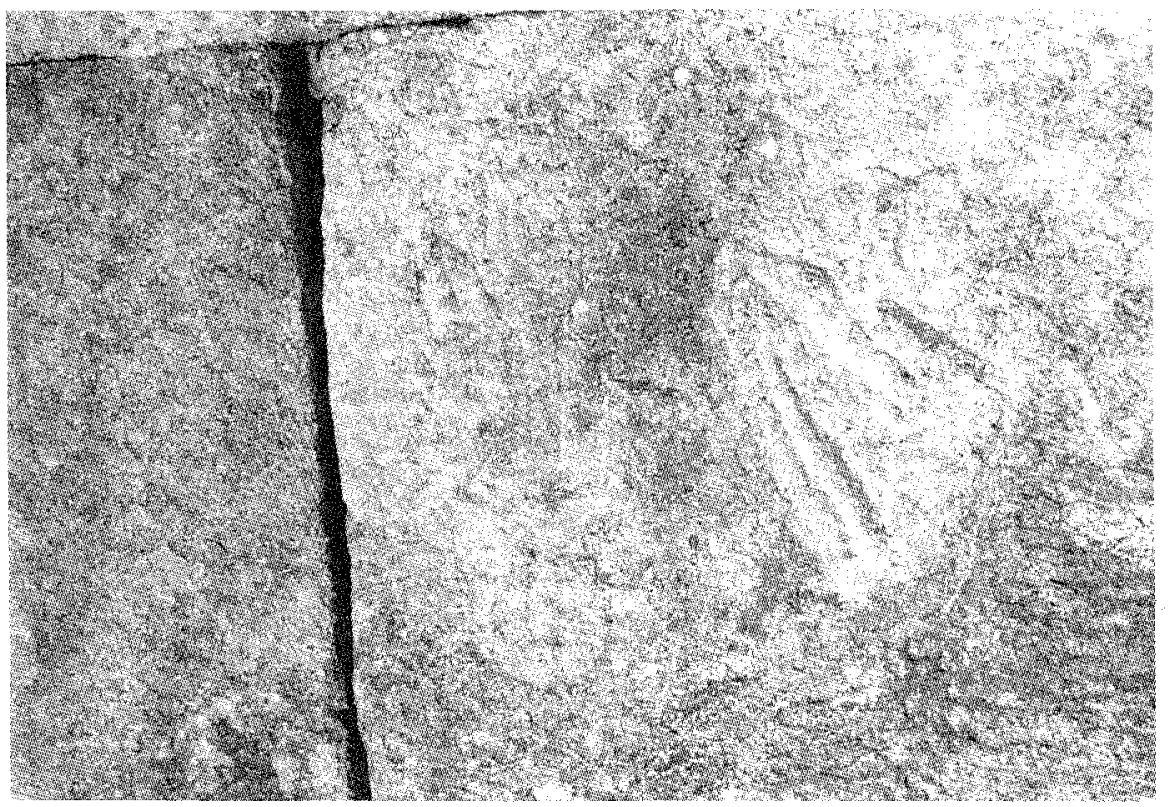

Lám. V.1. Santa Eulalia (tullidos)

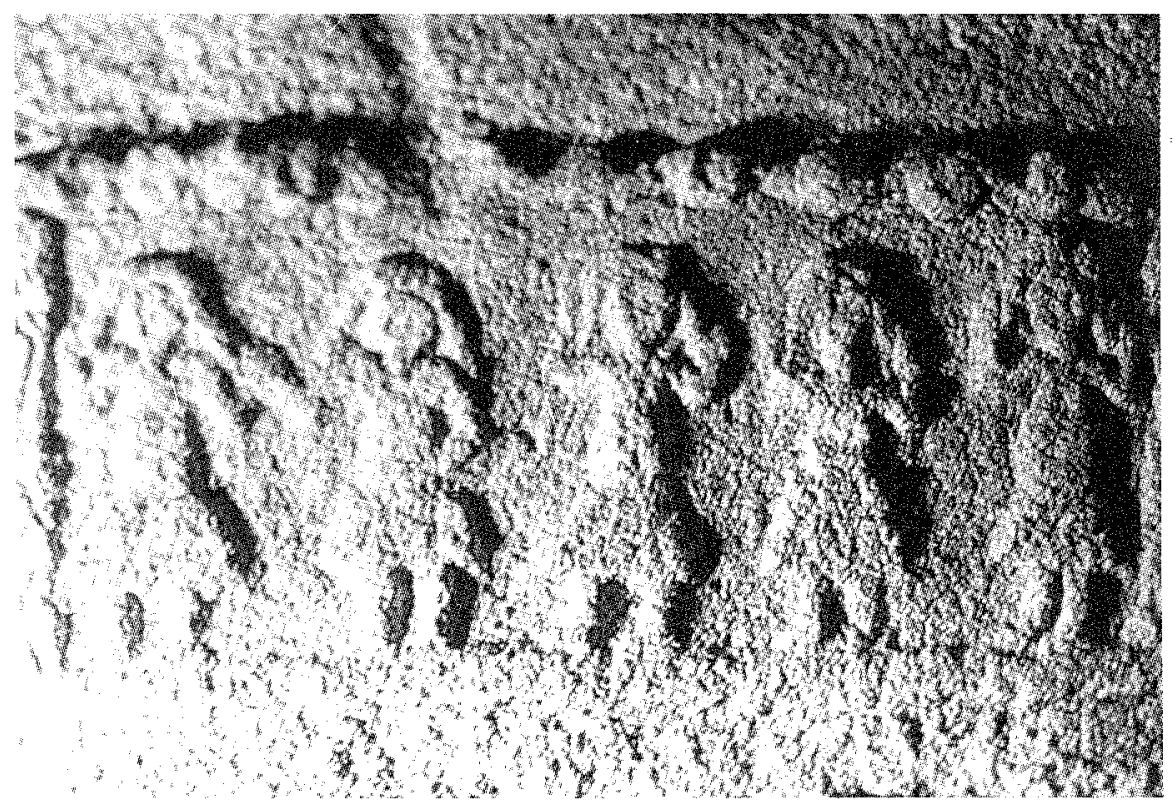

Lám. V.2. Santa Eulalia (danzantes). 
Pero, ¿que es nuestro relieve, un exvoto o un fetiche? Más concretamente, ¿fueron labrados estos relieves con finalidad cultual o son exvotos producto del agradecimiento? Creemos que lo primero, porque, aunque en el caso de la escena descrita podría pensarse en una ejecución posterior al levantamiento de la fábrica del edificio, dado el escaso resalte del relieve, en los demás no es posible suponer una ejecución in situ y tras la construcción. La única duda que subsiste es si pertenecieron al friso de una edificación anterior, siendo reaprovechados en la segunda fase, o fueron labrados expresamente para ésta. Existen razones serias para la formulación de ambas suposiciones. Pero sigamos con la descripción de los relieves.

En la parte exterior del gran pilastrón norte del pórtico o atrio existen dos relieves que se corresponden, a similar altura, con otros dos semejantes del pilastrón sur. El superior representa cinco figuras danzantes (lám. $\left.V_{s} 2\right)$ de melena corta y vestimenta hasta las rodillas, como si de niñas se tratase. Enmarca la escena una rama de hedera. El inferior representa una figura evidentemente femenina, que sostiene con ambas manos, y sobre la cabeza, una guirnalda perfectamente arqueada y festoneada en ambas caras con baquetones ondulados que se unen por la base sin solución de continuidad, como si de un circulo doblado sobre sí mismo se tratase $(l a m . V I, 1)$. Apenas son reconocibles los rasgos de la cara, pero si los bucles de una melena perfectamente ondulada y muy del gusto de la moda constantiniana y posterior. La figura aparece vestida con túnica larga, que, sin embargo, se muestra totalmente abierta por la parte anterior, dejando al descubierto un abultado abdomen, signo probable, para nosotros, de gravidez. El edículo de enmarcamiento se compone de dos columnillas de orden jónico y fuste estriado, que recibe transversalmente un arquitrabe.

El pilastrón de la izquierda ofrece dos representaciones similares. La superior, muy destruida y dificilmente reconocible, es un remedo de su homóloga de la derecha, pero, contra lo que opina la mayoría de los tratadistas, dista bastante de ser idéntica. En efecto, las figuras aquí representadas llevan túnica larga, variando tambien los gestos y las actitudes, que ahora son de mano izquierda en jarras sobre la cintura. De todas maneras, el carácter festivo de los gestos es evidente aquí tambien, pero ya no parece tratarse de figuras infantiles sino de personas adultas.

La inferior es tambien en este caso una réplica de la correspondiente del pilastrón derecho, pero con sustanciales diferencias que ahora intentaremos subrayar (lám. VI,2). Ciertamente, el enmarque arquitrabado es idéntico e idéntica la disposición de la guirnalda, pero no lo son ni el rostro ni el vestido. El rostro, porque ya no se perciben bucles y sí so- 
Culto a las aguas y divinidades orientales en el Lugo romano ...

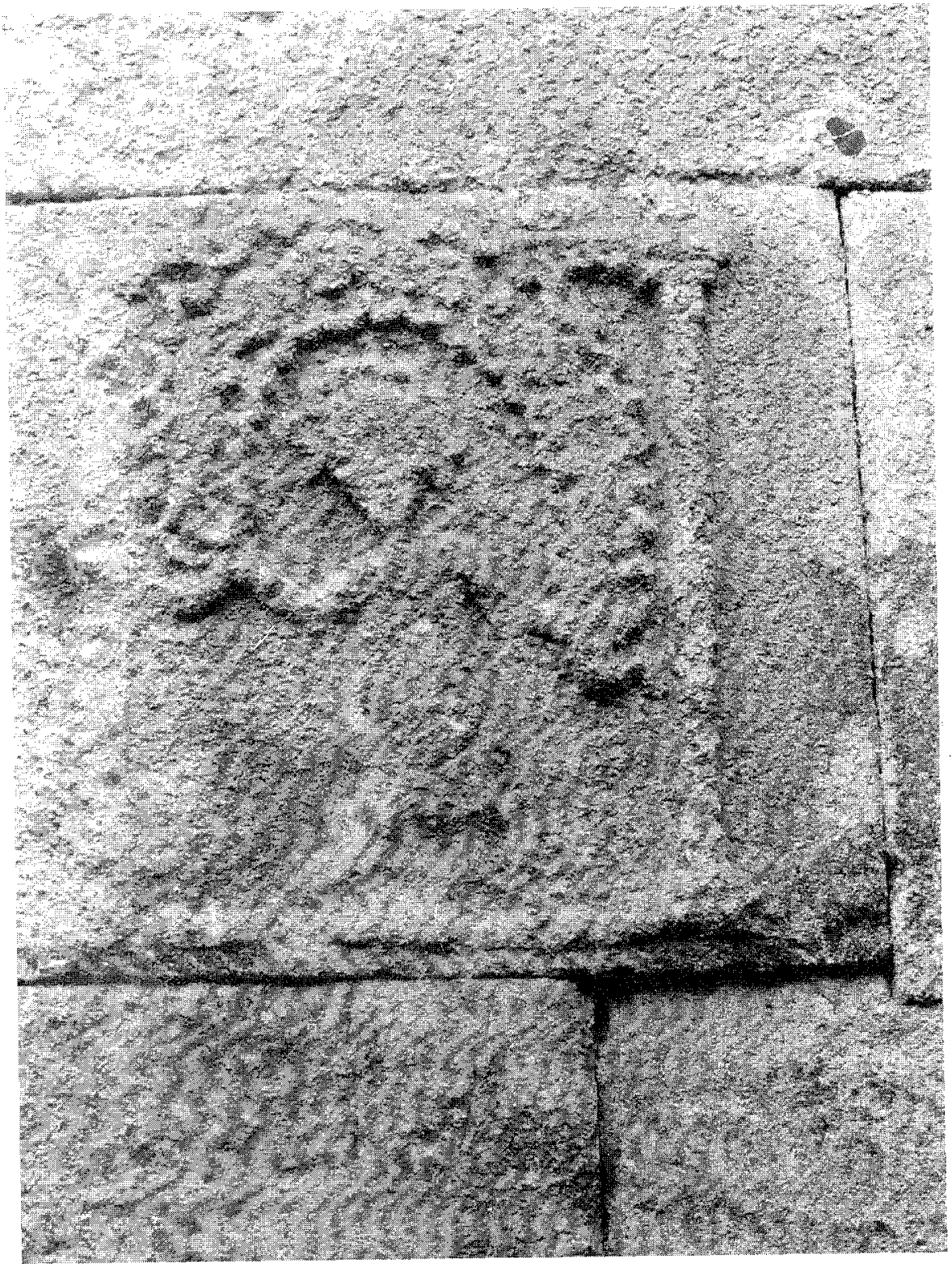

Lám. VI.1. Santa Eulalia (danzantes). 


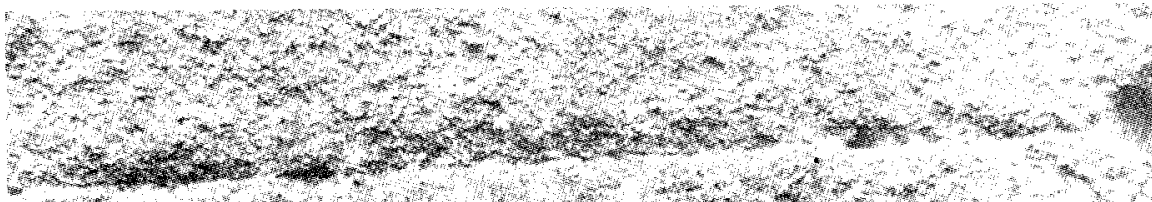

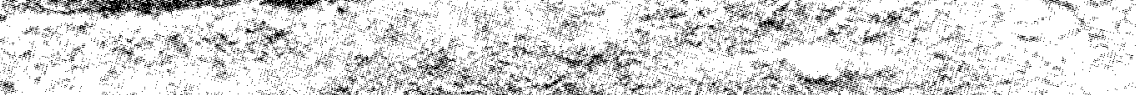
H. H

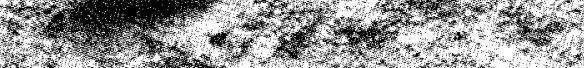

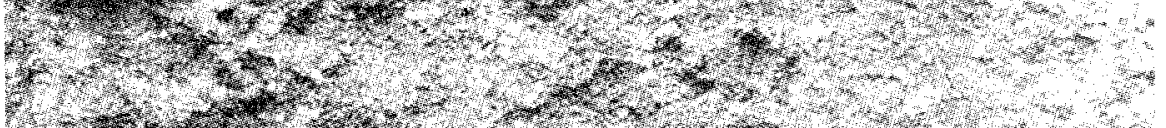
Mr.

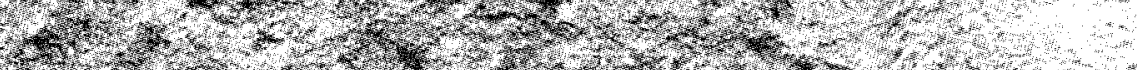

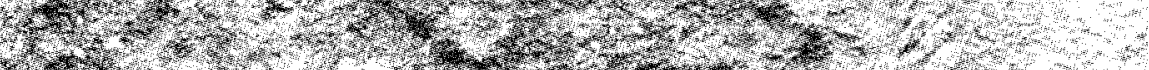
Wrat

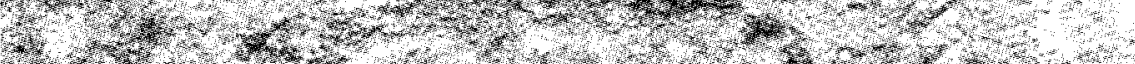

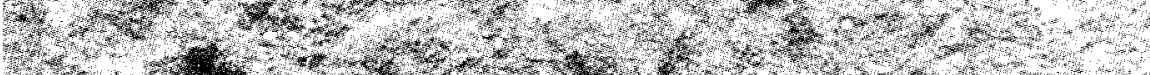
Mr Mr m

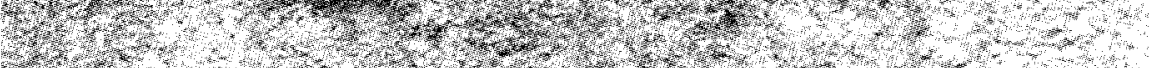

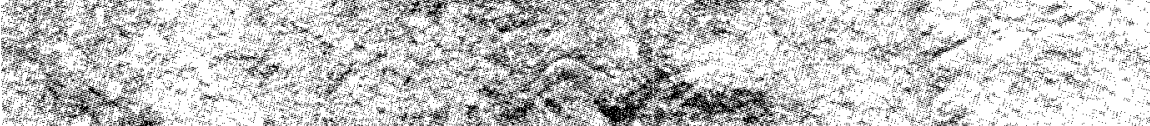

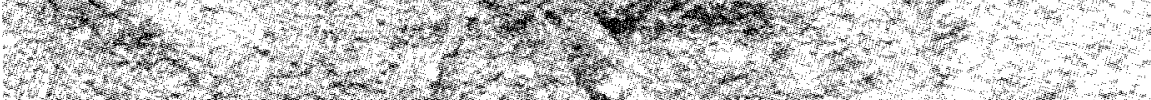
Mr Pr

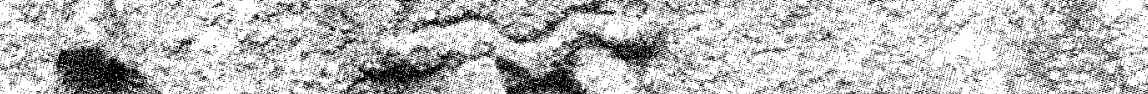

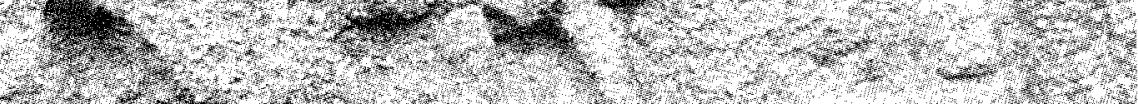

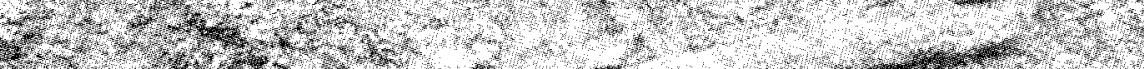

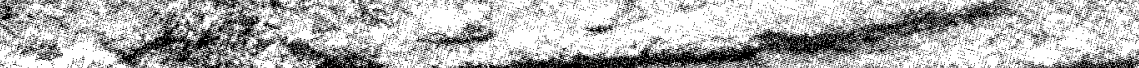

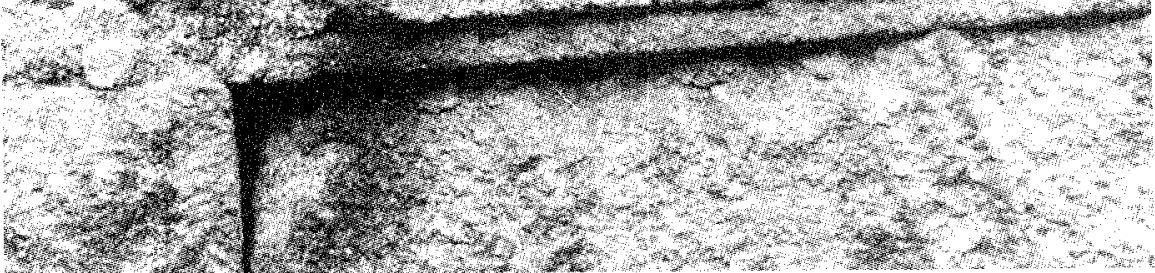

Lám. VI.2. Santa Eulalia (danzante). 
Culto a las aguas y divinidades orientales en el Lugo romano ...

lamente el pelo corto de un varón; el vestido, porque, no existiendo el gran escote abdominal, se compone ahora de chitón corto, que le llega hasta la cintura, y de una falda que le tapa hasta la rodilla, mostrándose festoneada con una incisión trapezoidal. Todavía restan por describir otros relieves ejecutados en los sillares del interior del nártex, como el ánade posada sobre el nido asentado en un tronco o el avestruz en movimiento, y dispuestos de manera aparentemente anárquica, pero la profundización en su simbologia nos llevaría a cubrir un espacio en esta publicación conjunta del que ciertamente no disponemos.

Todos estos relieves, tanto los de silueta antropomorfa como los de silueta zoomorfa, pueden ser relacionados con los efectos benefactores de las divinidades orientales. La escena de los tullidos, la mujer grávida, el coro de danzantes adultos o infantiles entra de lleno en el contexto de favores otorgados a los mortales por Isis y Serapis a través del agua del Nilo, real o «sacramental». Diodoro (1.36.2) y Ammiano Marcelino (22.15.3) afirmaban que el Nilo era famoso por los favores que obtorgaba. $Y$ en esta línea F. J. Dölger ${ }^{45}$ puntualiza que la gente estaba interesada en el contacto con el agua del Nilo por las siguientes razones: era preservativa ante la enfermedad y suministradora de la salud, la prosperidad y la vida, entendida esta última, según unos, en el sentido trascendental (Bonneau) ${ }^{46}$ y según otros referida al más acá, a la vida corporal ${ }^{47}$. Que el Nilo fue conocido en el mundo antiguo como la quinta esencia de la fecundidad de la tierra y de la multiplicación de animales de toda especie lo testifican hasta la saciedad escritores como Esquilo (Pers. 33), Virgilio (Georg. 4.287-292), Themistio (Or. 24.305d) o Pomponio Mela (1.9.52), por no citar sino a los más conocidos. Pero esta fecundidad proverbial se hacia extensible a los humanos, de tal manera que, según Aristóteles (His. An. 7.4.584) las mujeres egipcias tenian frecuentemente trillizos en los partos, cifra que, para un caso concreto, eleva Trogo Pompeyo a siete criaturas de un solo parto (Est. 15.1.22). Tal vez, sería en esta dirección que podria intentar explicarse la presencia de las cinco figuras infantiles sobre el relieve de la mujer grávida, pero no contamos con datos evidentes para ello.

En la misma línea de beneficios, Séneca (Q. Nat. 3.25.11) asevera que las aguas del Nilo curaban la esterilidad. Incluso Theophirasto (cit. en Athenaeus, 2.15.41) llegó a decir que el agua del Nilo regulaba la función

${ }^{45}$ Dölger, Franz J., «Nilwaser und Taufwaser» Ant. Christ., 5, 1936, pág. 174.

${ }^{46}$ Bonneau, D., La crue du Nil, divinite égyptienne à travers mille ans d'histoire (332 av. -641 ap. J. C.). París 1964.

${ }^{47}$ WILD, R., Water. ..., 99-100. 
de los órganos interiores del cuerpo, constituyendo un magnífico laxante. Pero eran las ideas de fertilidad y fecundidad, asociadas a las aguas del Nilo, más que las de la salud corporal, que no se excluye sino todo lo contrario, así como las de la vida en el más allá, las que predominaban en el conocimiento que de las virtudes del río poseian amplias masas del mundo romano imperial. Nada de extrañar, por lo tanto, la presencia de dos posibles santuarios relacionados con divinidades egipcias en una capital romana de indudable importancia a partir del siglo III como Lucus Augusti.

En resumen, los relieves existentes en el monumento de Bóveda parecen querer transmitir un múltiple mensaje relacionado con la vida y la salud: los dos paralíticos buscan la curación, los danzantes predican con su actitud la alegría, la mujer grávida y su compañero harian, tal vez, alusión a las ideas de fecundidad y fertilidad y, finalmente, los relieves con aves serían símbolo de la inmortalidad y la resurrección, todo el elenco de bienes que predican las religiones orientales, egipcias especialmente, en el siglo ili de la era frente a unos cada vez más esclerotizados cultos oficiales.

De todo lo anteriormente expuesto se deduce que, si la epigrafía testimonia diafanamente una notable presencia de divinidades egipcias en todo el Noroeste, y más concretamente en los cuatro centros urbanos de Lucus, Asturica, Bracara y Aquae Flaviae, ¿por qué no admitir la existencia en nuestra región de santuarios dedicados a tales divinidades? Pues bien, candidatos legítimos a tal posibilidad pudieran ser, por sus caracteristicas tanto intrínsecas como extrínsecas, los dos ejemplos lucenses que hemos, brevemente, estudiado.

\section{RESUMEN}

La aparición, en la ciudad de Lugo, de una piscina de época romana con los mascarones de entrada y calida representando una esfinge y un carnero, respectivamente, ha dado motivo al autor de estas páginas a formular la hipótesis de que podría tratarse de un estanque cultual relacionado con divinidades orientales, si bien el carácter funerario del mismo quedaria, a la vez, patente. Por similitud, se hace extensiva dicha hipótesis al edificio semihipogeo de Santa Eulalia de Bóveda, también en las cercanías de Lugo. 
Culto a las aguas y divinidades orientales en el Lugo romano ...

ABSTRACT

The discovery, in the city of Lugo, of a swimming pool of Roman times, with its entrance and exit figureheads representing, respectively, a sphinx and a ram, has motivated, the author of these pages, to formulate the hipothesis that it could be a pool connected with oriental divinities even thoug its funerary character is evident. The same can be said concerning the semi-hypogeum of Santa Eulalia de Bóveda, as well near the city of Lugo. 